\title{
A case report of hydatidiform mole: A Diagnostic Dilemma
}

\author{
Bharadwaj M. ${ }^{1}$, Shinde T. ${ }^{2}$
}

${ }^{1}$ Dr. Malini Bharadwaj, Professor \& Head, ${ }^{2}$ Dr. Tarani Shinde, Resident; both authors are attached with Department of Obstetrics \& Gynecology, J.K. Hospital \& L.N. Medical College, Bhopal, MP, India.

Correspondence Author: Dr. Tarani Shinde, Resident, Department of Obstetrics \& Gynecology, J.K. Hospital, L.N. Medical College, Bhopal, India. E-mail: dr.nami0302@gmail.com

\begin{abstract}
Molar pregnancy is a part of gestational trophoblastic disease, and can rarely be associated with hyperthyroidism. We report a case of complete hydatidiform mole who initially presented as one and half month amenorrhea and bleeding per vaginum, with an ultrasonography report suggestive of multiple gestational sacs without any fetal pole, leading to a provisional diagnosis of threatened abortion. Then, routine investigations were done and raised beta HCG value were suggestive of choriocarcinoma and hydatidiform mole which was later confirmed by histopathological examination.
\end{abstract}

Keywords: Molar pregnancy, Gestational trophoblastic disease, Hyperthyroidism, Hydatidiform mole

\section{Introduction}

Gestational trophoblastic disease (GTD) is a rare complication of pregnancy that may be associated with hyperthyroidism. The incidence of hydatidiform mole in the United States and other developed countries is about 1 in 1500 live births. Complete moles have highest incidence of thyrotoxicosis and predominantly affect younger women and present with vaginal bleeding most of the time [1].

Molar pregnancy is common in some parts of Asia, with incidence as high as 1 in 400 pregnancies in India. Gestational trophoblastic disease comprises a group of disorders that arise from placental trophoblastic tissues where there are partly degenerative and partly proliferative changes in the young chorionic villi. GTD lesions are histologically indistinct. They include benign lesion which comprises of complete and partial hydatidiform mole and also malignant lesions consisting of invasive mole, choriocarcinoma, epithelioid trophoblastic tumor and placental site trophoblastic tumor $[1,2]$.

Thesemalignant lesions can transform into invasive gestational trophoblastic neoplasia. In general complete moles are 46XX or 46XY karyotype and chromosomes are entirely of paternal origin.Partial moles have triploid karyotype (69XXY OR 69XYY) with one maternal and usually two paternal haploid chromosomes [3].

\section{Case Report}

A 20 year old women, gravida 2 para 1, presented to the OPD at JK Hospital with history of one and half month amenorrhea and UPT positive with complaint of lower abdominal pain and bleeding per vaginum since 15 days. She carried a USG report which showed multiple gestational sacs without any fetal pole. On examination, patient was stable. The patient's vital signs showed blood pressure of $122 / 76 \mathrm{mmHg}$, heart rate of $82 / \mathrm{min}$ and respiratory rate of $15 / \mathrm{min}$. On per abdomen examination- uterus was of 16 week size, soft. On local examination-slight bleeding was present, on per speculum examination cervix appeared bluish, and on per vaginal examination uterus size was 16 weeks, bilateral fornix were free and non tender.

A.Investigations- Ultrasonography findings showed bulky uterus with significant heteroechoic debris collection along with color pick up suggestive of hematometra. Another USG finding was suggestive of multiple gestational sacs without any fetal pole.

Manuscript received: $30^{\text {th }}$ January 2019

Reviewed: $7^{\text {th }}$ February 2019

Author Corrected: $14^{\text {th }}$ February 2019

Accepted for Publication: $18^{\text {th }}$ February 2019 


\section{Case Report}

Initial laboratory investigations included normocytic hypochromic anemia with haemoglobin level of $8 \mathrm{~g} / \mathrm{dl}$ (normal range $12.0-16.0 \mathrm{~g} / \mathrm{dL}$ ), mean corpuscular volume of 81.1 (normal range 80-100 fL), and normal leucocyte count. Her TSH was low $(<0.05 \mathrm{uIU} / \mathrm{m})$ and beta HCG value was found to be very high $(>200000)$.
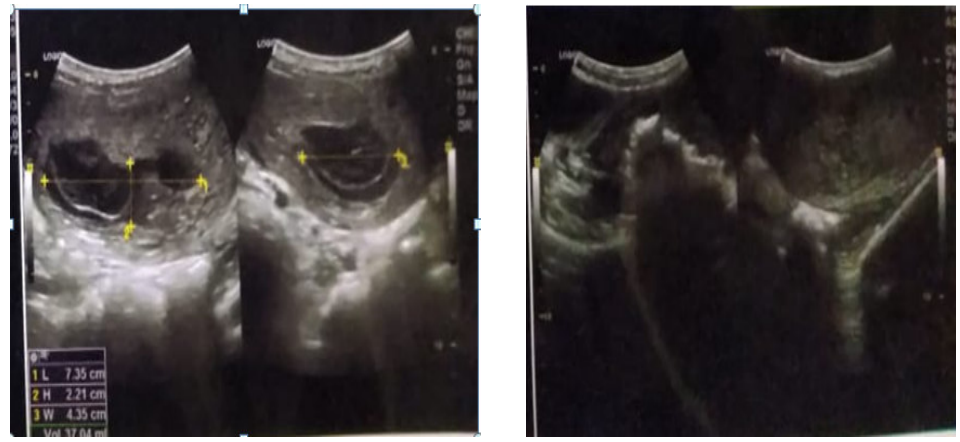

Fig1: Ultrasonography suggestive of multiple gestational sacs with no fetal pole seen

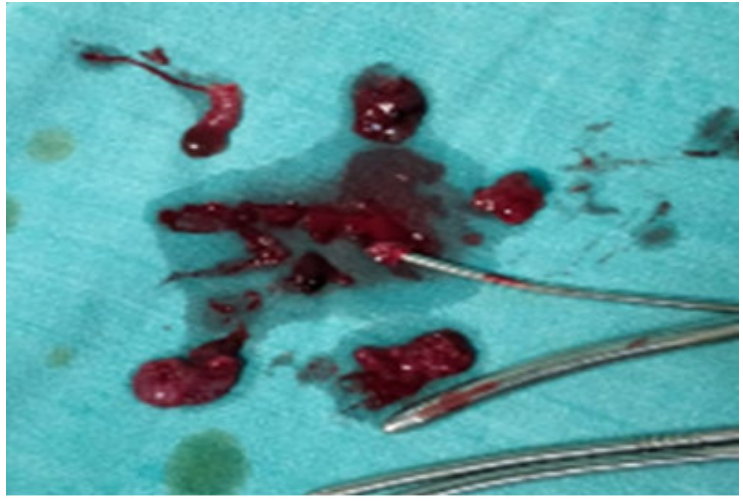

Fig2: Products obtained after suction and evacuation, no vesicles seen.

B. Differential diagnosis- Onthe basis of investigations differential diagnosis of hematometra, or multiple gestation with threatened abortion was made. Due to high beta hcg, diagnosis of choriocarcinoma and hydatidiform mole was also kept in mind. In order to confirm the diagnosis, diagnostic and therapeutic suction evacuation was planned.

C. Treatment- Two units blood (PRBC) was transfused to correct anemia. Diagnostic and therapeutic suction evacuation was done under short GA. Tissues and blood clots obtained were resembling RPOC with no vesicles seen and were sent for histopathological examination.

D. Outcome and followup- The subsequent histopathological report showed the features of complete hydatidiform mole and after routine investigations, LFT and RFT were done, 50mg prophylactic methotrexate was given in tramuscularly. Prompt treatment with methotrexate was given because patient was non compliant and there was risk of lost to follow up. Nonetheless, patient was counseled for all the risks and follow up beta hcg was advised.

\section{Discussion}

Hydatidiform mole is principally a disease of chorion. It is best regarded as a benign neoplasia with malignant potential. The most common features are vaginal bleeding with lower abdominal pain and expulsion of grape like vesicles. This is a rare complication of pregnancy that may be associated with hyperthyroidism.

A similar case report of hydatidiform mole with hyperthyroidism was seen by Bhat, S and Maletkovic, J in which the patient presented with history of nausea, weight loss, and intermittent vaginal bleeding. Once investigations confirm the diagnosis, treatment consisted mainly of suction and evacuation. Follow up beta HCG is done weekly until levels reach the normal range. Many times for diagnosis of hydatidiform mole and choriocarcinoma ultra sonography alone is not helpful so to confirm the diagnosis we have to go for histopathological examination[4,5]. 


\section{Case Report}

Surgical pathologists often encounter hydropic villi in products of conception at the first trimester and must determine whether the villi represent complete hydatidiform mole (CM), partial hydatidiform mole (PM), or hydropic abortion (HA). The distinction between these is important for determining the appropriate treatment of patients. Fukunaga M, Katabuchi $\mathrm{H}$ et al study assessed interobserver and intraobservervariability. The addition of ploidy data resulted in a significant improvement in concordance. Ploidy study is useful in equivocal cases. Significant interobserver and intraobserver variability was observed even among placental pathologists. New histologic criteria adaptable to differentiation of early lesions are needed [6].

Knowledge of the nuclear DNA content of a hydatidiform mole is extremely useful in distinguishing a partial hydatidiform mole from a complete hydatidiform mole. Flow cytometry can be applied to both fresh or frozen tissue as well as to formalin-fixed, paraffin-embedded samples. Methodologies for extracting, staining, and analyzing nuclei are relatively simple and inexpensive, and results are accurate and reproducible. When combined with clinical history and careful gross and microscopic examination, nuclear DNA content should serve as a very strong indicator of final diagnosis [7].

Four difficult differential diagnoses in gynecologic and obstetric pathology are reviewed. These include (1) sarcoma-like mural nodule in ovarian tumors versus ovarian sarcomas, (2) early blastocyst versus choriocarcinoma, (3) hydropic abortus versus partial hydatidiform mole, and (4) regressing implantation site versus placental site trophoblastic tumor[8,9].

Howat AJ, Beck S assessed the degree of difficulty in diagnosing partial mole by analyzing intraobserver and interobserver agreement among a group of pathologists for these diagnoses. Fifty mixed cases of partial mole, complete mole, and non-molar pregnancy were submitted to seven histopathologists, two of whom are expert gynaecological pathologists; the other five were district general hospital consultants. In only 35 out of 50 cases was there agreement between five or more of the seven participants. Agreement between the expert gynaecological pathologists was no better than for others in the group. Interestingly, the intraobserver agreement for each pathologist was good to excellent. These results imply that the reported histological criteria are either not being applied consistently or that they are lacking in practical use. An atypical growth pattern of trophoblast, rather than the polar accentuation seen in normal first trimester pregnancies, seems to be the important diagnostic histological feature for partial mole. Ploidy studies might also help with problem cases [10].

\section{Conclusion}

Ploidy study is useful in equivocal cases. The author's own interpretation and recommendations are presented. The distinction between complete hydatidiform mole (CM), partial hydatidiform mole (PM), or hydropic abortion (HA) is important for determining the appropriate treatment of patients. Sometimes only USG findings along with BHCG are not alone helpful in establishing the diagnosis and typical snowstorm appearance in USG is also not very common, so to confirm the diagnosis histopathological examination is must.

Funding: Nil, Conflict of interest: Nil Permission from IRB: Yes

Ethical Approval: Yes

\section{References}

1. Seckl MJ, Gillmore R, Foskett M, et al. Routine terminations of pregnancy--should we screen for gestational trophoblastic neoplasia? Lancet. 2004 Aug 21-27; 364(9435):705-7.DOI:10.1016/S0140-6736(04) 16898-0

2. Brown J, Naumann RW, Seckl MJ, et al. 15years of progress in gestational trophoblastic disease: Scoring, standardization, and salvage. Gynecol Oncol. 2017 Jan; 144 (1): 200-207. doi: 10.1016/j.ygyno.2016.08.330. Epub 2016 Oct 13.

\section{Berek\&NovaksGynaecology15thedition,p.2537-2542}

4. Santaballa A, García Y, Herrero A, et al. SEOM clinical guidelines in gestational trophoblastic disease (2017). Clin Transl Oncol. 2018 Jan; 20(1):38-46. doi: 10. 1007/s12094-017-1793-0. Epub 2017 Nov 17.

5. Bhat, S., Maletkovic, J. A Hydatidiform Mole Can Cause Severe Gestational Hyperthyroidism. Clin Thyroidol 2013; 25:298-300.

6. Fukunaga M, Katabuchi H, Nagasaka T, Mikami Y, Minamiguchi S, Lage JM. Interobserver and intraobserver variability in the diagnosis of hydatidiform mole. The American journal of surgical pathology. 2005 Jul 1;29(7):942-7. 


\section{Case Report}

7. Lage JM, Popek EJ. The role of DNA flow cytometry in evaluation of partial and complete hydatidiform moles and hydropic abortions. In Seminars in diagnostic pathology 1993 Aug (Vol. 10, No. 3, pp. 267-274).

8. Lage JM. Diagnostic dilemmas in gynecologic and obstetric pathology. Semin Diagn Pathol. 1990 May; 7 (2): 146-55.
9. Conran RM, Hitchcock CL, Popek EJ, Norris HJ, Griffin JL, Geissel A, McCarthy WF. Diagnostic considerations in molar gestations. Human pathology. 1993 Jan 1;24(1):41-8.

10. Howat AJ, Beck S, Fox H, Harris SC, Hill AS, Nicholson CM, Williams RA. Can histopathologists reliably diagnose molar pregnancy? Journal of clinical pathology. 1993 Jul 1;46(7):599-602.

\section{How to cite this article?}

Bharadwaj M, Shinde T. A case report of hydatidiform mole: A Diagnostic Dilemma. Obs Rev:J obstet Gynecol 2019;5 (1):26-29.doi:10.17511/joog.2019.i01.05. 